\title{
Características cefalométricas do padrão face longa*
}

\author{
Mauricio de Almeida Cardoso**, Francisco Antonio Bertoz ${ }^{\star \star *}$, Leopoldino Capelozza Filho****, \\ Sílvia Augusta Braga Reis ${ }^{\star \star \star \star \star}$
}

\section{Resumo}

Este estudo determinou as características cefalométricas dos indivíduos portadores de Padrão Face Longa em comparação com indivíduos Padrão I. Um total de 73 telerradiografias em norma lateral, sendo 34 Padrão Face Longa e 39 Padrão I, foram selecionadas com base na morfologia facial, não considerando as relações oclusais e sagitais. Foram avaliados: padrão de crescimento facial, alturas faciais anteriores e posterior, relação maxilo-mandibular, além das relações dentárias com suas bases apicais. De uma forma geral, os indivíduos Padrão Face Longa apresentaram grandes desvios em relação aos indivíduos Padrão I, sendo a doença decorrente de um desequilíbrio entre os componentes verticais. Pôde-se observar que os valores das grandezas AFAT, AFAI, AFATperp, AFAIperp, 1-PP, 6-PP, 1-PM, SNB, ANB, ângulo goníaco, ângulo plano mandibular, além das proporções AFAI/AFAT e AFAIperp/AFATperp, estavam significantemente alterados para os indivíduos Padrão Face Longa. Com base nos resultados obtidos neste estudo, verificou-se que esses indivíduos caracterizavam-se pelo padrão de crescimento vertical e por um aumento da altura facial anterior inferior - conseqüentemente, da altura facial anterior total - estando a deformidade localizada abaixo do plano palatino. Foram observados ainda um retrognatismo maxilar e mandibular, além da presença de extrusão dentária anterior (superior e inferior) e póstero-superior, com os incisivos superiores bem posicionados em suas bases e os inferiores lingualizados.

Palavras-chave: Cefalometria. Deformidades. Ortodontia corretiva. Padrão face longa.

\section{INTRODUÇÃO}

A face longa é uma deformidade com envolvimento esquelético, de prognóstico estético desfavorável. Manifesta-se precocemente, mantendo-se característica do indivíduo ${ }^{30}$, sendo magnificada ou não na adolescência ${ }^{15}$. Esta deformidade vertical pode estar presente nas três relações dentárias sagitais, sendo, contudo, mais associada às discrepâncias sagitais Classe $\mathrm{II}^{1,9,11,39,47}$.

As crianças e adultos, que manifestam esse exces-

\footnotetext{
* Resumo da Dissertação apresentada à Faculdade de Odontologia do "Campus de Araçatuba - UNESP", para obtenção do grau de MESTRE EM ODONTOLOGIA (Área de Concentração: Ortodontia).

** Mestre e Doutorando em Ortodontia pela Universidade Estadual Paulista, UNESP - Araçatuba.

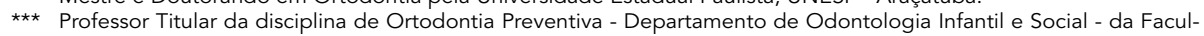
dade de Odontologia de Araçatuba - UNESP. Professor do Programa de Pós-graduação em Ortodontia da Faculdade de Odontologia de Araçatuba - UNESP.

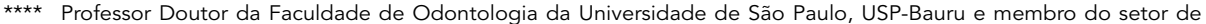
Ortodontia do HRAC da Universidade de São Paulo, USP - Bauru. Professor do Programa de Pós-graduação em Ortodontia da Faculdade de Odontologia de Araçatuba - UNESP.

$\star \star \star \star \star$ Especialista em Ortodontia pela PROFIS-USP-Bauru; Mestre em Ortodontia pela Universidade Metodista de São Paulo; Doutoranda em Ortodontia pela USP-São Paulo; Professora Assistente do Departamento de Ortodontia da Universidade Metodista de São Paulo.
} 
sivo crescimento vertical da face, apresentam uma aparência característica, descrita na literatura como "síndrome da face longa"5,39 tipo facial hiperdivergente $^{17,26}$ e, recentemente, Padrão Face Longa ${ }^{9,11}$. Segundo a divisão de estatística na área da saúde dos EUA, a incidência desse tipo de displasia vertical é de $1,5 \%$, aproximadamente, na população mundial ${ }^{17}$.

A principal queixa desses pacientes é o excesso de exposição dos dentes anteriores superiores e gengiva, com os lábios em repouso ${ }^{1}$. Um tratamento ortodôntico-cirúrgico combinado, freqüentemente está indicado para a obtenção de uma adequada estética, função e estabilidade ${ }^{9,11,15}$. Segundo Van der Linden $^{43}$, as limitações do tratamento conservador ortodôntico e ortopédico são óbvias, pois a supressão do desenvolvimento vertical em fases ativas do crescimento é seguida por um aumento excessivo na altura inferior da face nos anos seguintes. Em outras palavras, o crescimento remanescente cancela o efeito do tratamento sobre a morfologia esquelética. A Cirurgia Ortognática está definitivamente indicada para o restabelecimento estético e funcional em pacientes com desfiguração facial ${ }^{12}$.

O diagnóstico do Padrão Face Longa baseia-se nas avaliações da morfologia facial e da Cefalometria, ${ }^{9,11}$. A análise facial permite identificar inúmeras características comuns a estes indivíduos, tais como: ausência de selamento labial passivo e contração do músculo mentoniano durante o fechamento labial ${ }^{1}$, além de uma grande exposição dos incisivos superiores, quando os lábios encontram-se em repouso, e gengival, durante o sorriso ${ }^{1,5,14,39,47}$. O nariz é longo, observando-se estreitamento das bases alares, e o zigomático é geralmente plano. $\mathrm{O}$ terço inferior da face é longo, resultando numa aparência retrognata da mandíbula ${ }^{1,14,39,41,47}$.

A Cefalometria constitui um instrumento necessário para definir, localizar e quantificar a desarmonia esquelética, que pode estar associada a um crescimento horizontal do côndilo ${ }^{6}$ e/ou a um crescimento posterior excessivo da maxila ${ }^{39,40}$. Cada condição exibe um diferente prognóstico para sua correção.

Com relação às características cefalométricas, observa-se aumento da altura facial anterior total e da altura facial anterior inferior $16,18,19,22,27,28,38,39,41$. A altura facial anterior superior é geralmente normal ${ }^{1,5,17,39}$, mas a proporção entre os terços médio e inferior encontra-se reduzida ${ }^{4,20,47}$.

A superfície oclusal, bem como os ápices radiculares dos incisivos e molares superiores, podem estar mais distantes do plano palatino ${ }^{20,22,38,41,47}$. $\mathrm{O}$ ângulo do plano mandibular encontra-se aumentado $2,4,5,15,16,17,20,27,28,33,47$ assim como o ângulo goníaco $^{2,15,18,28,38,41}$.

Um retroposicionamento da mandíbula em relação à base do crânio é normalmente observado 1,16,17,22,41,47 . A maxila, contudo, normalmente encontra-se bem posicionada em relação à base do crânio ${ }^{1,16,17}$.

São poucos os trabalhos encontrados na literatura que relatam a utilização de amostras calcadas em avaliações realizadas em pacientes Padrão Face Longa com indicação de tratamento ortodônticocirúrgico ${ }^{1,5,14,18,19,45}$. Esses trabalhos foram realizados com amostras selecionadas conforme critérios oclusais ${ }^{8,17,20,27,28}$ ou cefalométricos ${ }^{13,22,31,33,42}$, comprovadamente ineficazes na classificação dos pacientes com problemas nas suas relações esqueléticas, ao invés de utilizarem-se do padrão facial propriamente dito $3,7,15,18,32$. Isso pode, conseqüentemente, acarretar inexatidão nas conclusões obtidas, ao não considerar o problema esquelético o fator primário no estabelecimento da displasia esquelética vertical 1,2,4,17,33,38,41,45,47.

Além disso, e por isso, poucos parâmetros cefalométricos confiáveis foram estabelecidos para a indicação de uma abordagem ortodôntico-cirúrgica, requerendo, assim, dados mais precisos para subsidiar o clínico no diagnóstico, na indicação de condutas clínicas e no planejamento das mesmas.

Diante de tal contexto, este trabalho tem por objetivo realizar um estudo das características cefalométricas em pacientes Padrão Face Longa com indicação de tratamento ortodôntico-cirúrgico. Para tal, realizou-se um estudo comparativo entre indivíduos Padrão Face Longa e Padrão I, utilizando-se como critério de seleção, para ambos os grupos, a morfologia facial. 


\section{MATERIAL E MÉTODO}

\section{Material}

\section{Amostra Padrão Face Longa}

Para o presente estudo transversal retrospectivo, foram selecionadas 34 telerradiografias cefalométricas em norma lateral do período pré-tratamento, com base em documentação já existente no Centro de Cirurgia e Ortodontia, da qual foram selecionados indivíduos de ambos os gêneros, brasileiros, leucodermas, portadores de Padrão Face Longa, com indicação para uma intervenção ortodônticocirúrgica. Dos indivíduos selecionados para essa amostra, 22 eram do gênero feminino $(64,71 \%)$ e 12 do gênero masculino $(35,29 \%)$ (Tab. 1$)$.

Todos os indivíduos selecionados apresentavam idades acima de 15 anos, com média de 22 anos e 2 meses ( $d p=7$ anos e 5 meses) para a amostra total, sendo 25 anos e 4 meses ( $d p=7$ anos e 4 meses) e 16 anos e 3 meses ( $d p=1$ ano e 3 meses) as médias e desvios-padrão, respectivamente, para os gêneros

\begin{tabular}{|c|c|c|c|}
\hline \multicolumn{4}{|c|}{ Tabela 1 - Freqüência dos gêneros feminino e masculino dos grupos Padrão I e Padrão Face Longa. } \\
\hline Padrão & Gênero feminino & Gênero Masculino & Total \\
\hline Grupo Padrão I & 26 & 13 & 39 \\
\hline Grupo Padrão Face Longa & 22 & 12 & 34 \\
\hline Total & 48 & 25 & 73 \\
\hline
\end{tabular}

\begin{tabular}{|c|c|c|c|c|}
\hline Gênero & Idade Média PI & Desvio-padrão & Idade média PFL & Desvio-padrão \\
\hline Feminino & 19a $7 m$ & 3a $1 \mathrm{~m}$ & $25 a 4 m$ & 7a $4 m$ \\
\hline Masculino & 22a 8m & 2a $5 \mathrm{~m}$ & $16 a 3 m$ & 1a $3 m$ \\
\hline Total & 22a $10 \mathrm{~m}$ & 2a $10 \mathrm{~m}$ & 22a $2 m$ & 7a $5 \mathrm{~m}$ \\
\hline
\end{tabular}
$\mathrm{a}=\mathrm{ano} ; \mathrm{m}=$ meses.

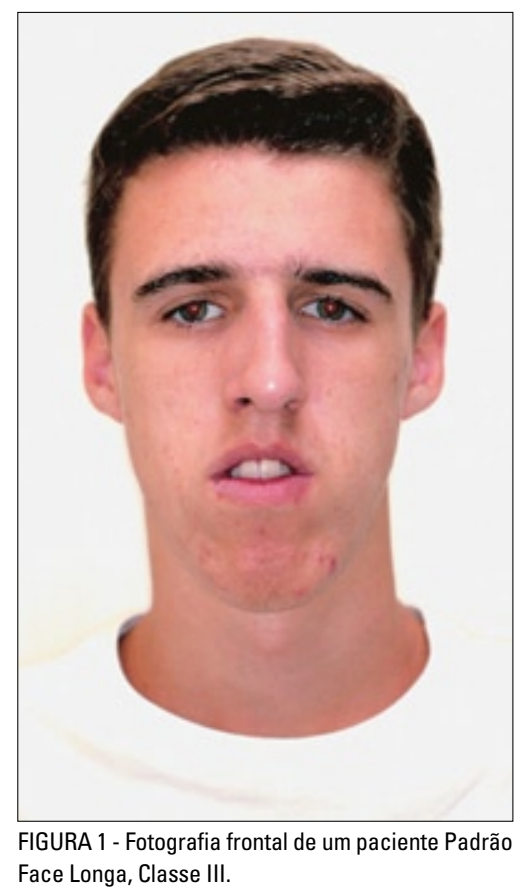

Face Longa, Classe III.

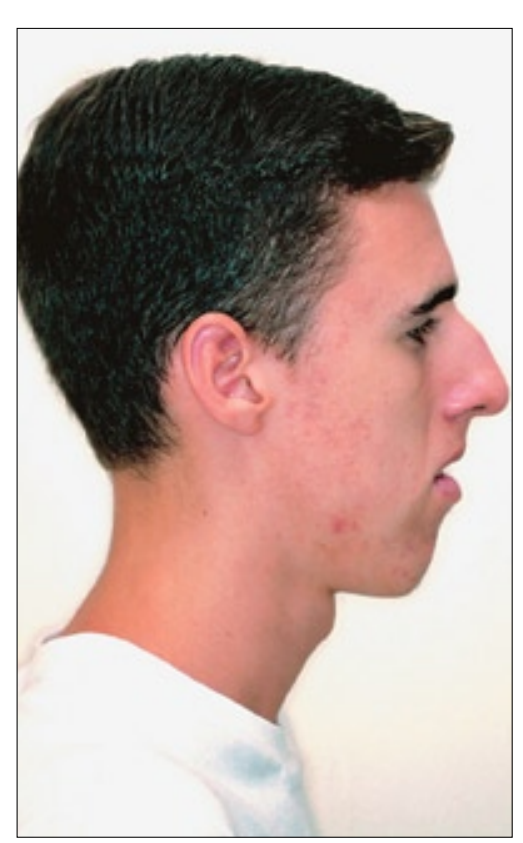

FIGURA 2 - Fotografia perfil de um paciente Padrão Face Longa, Classe III.

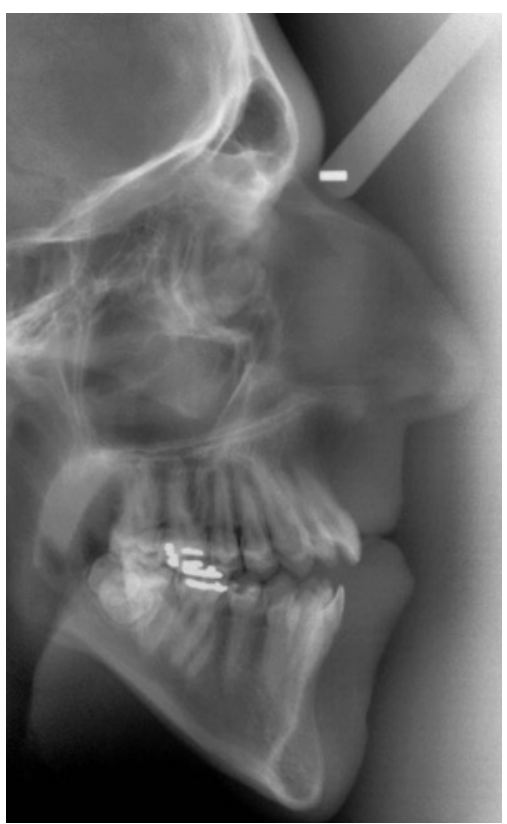

FIGURA 3 - Telerradiografia em norma lateral de um paciente Padrão Face Longa, Classe III. 
feminino e masculino (Tab. 2). Nenhum deles havia realizado tratamento ortodôntico e/ou ortopédico prévio e foram excluídos da amostra os indivíduos portadores de síndromes e/ou assimetrias.

Os critérios de seleção da amostra dos indivíduos Padrão Face Longa basearam-se na morfologia facial, não considerando as relações oclusais e sagitais, podendo ser observadas relações sagitais Classe I $(13,2 \%)$, Classe II $(71,0 \%)$ e Classe III $(15,8 \%)^{11}$. Todos os indivíduos dessa amostra, apresentaram indicação para o tratamento ortodôntico-cirúrgico, incluindo impacção maxilar, osteotomia sagital bilateral mandibular e mentoplastia sagital oblíqua.

$\mathrm{Na}$ avaliação da fotografia do perfil facial, as seguintes características foram observadas: 1) terço inferior da face aumentado em relação ao terço médio; 2) linha queixo-pescoço reduzida e ângulo queixo-pescoço fechado; 3) ausência de selamento labial passivo; 4) excesso de exposição dos incisivos superiores com os lábios em repouso (Fig. 1-3).

Os requisitos técnicos para seleção das telerradiografias cefalométricas laterais foram: a boa qualidade quanto à nitidez, posicionamento adequado da cabeça no cefalostato, implicando em coluna ereta e plano Horizontal de Frankfurt paralelo ao solo, um contraste das estruturas ósseas e de tecido mole, além de uma adequada condição de visualização dos ápices dos incisivos e molares superiores e inferiores.

\section{Amostra Padrão I - Grupo controle}

Os indivíduos selecionados para o grupo controle do presente estudo fizeram parte de uma amostra pré-existente, composta por 100 indivíduos leucodermas, brasileiros, adultos, portadores de selamento labial passivo, de ambos os gêneros ( 50 do gênero masculino e 50 do gênero feminino), sendo considerados 92 indivíduos esteticamente aceitáveis e agradáveis, pela análise facial subjetiva ${ }^{35}$. Essa amostra pré-existente foi composta por alunos, professores e funcionários da Universidade Metodista de São Paulo, com idade média de 23 anos e 7 meses, variando entre 18 e 36 anos. Dos 100 indivíduos, 39 foram considerados Padrão I, pois não apresentaram discrepância esquelética maxilo-mandibular sagital ou vertical quando avaliados na fotografia de perfil, tendo sido escolhidos de acordo com critérios morfológicos e não se considerando as relações oclusais. Esses indivíduos apresentavam: 1) perfil

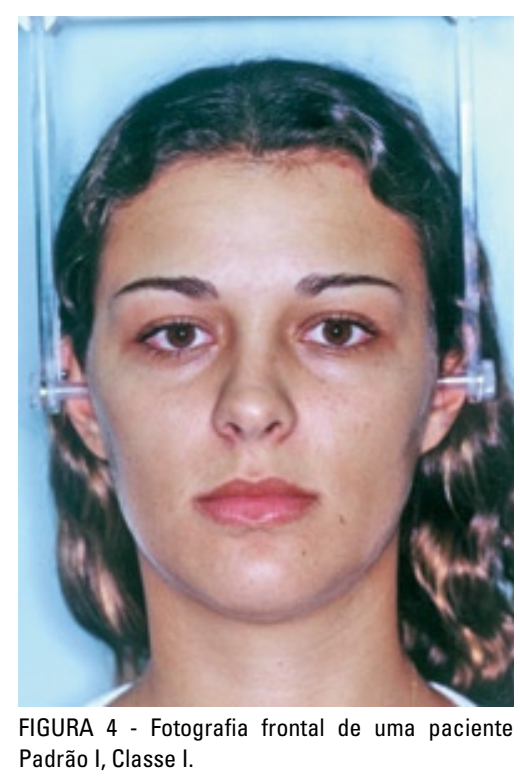

Padrão I, Classe I.

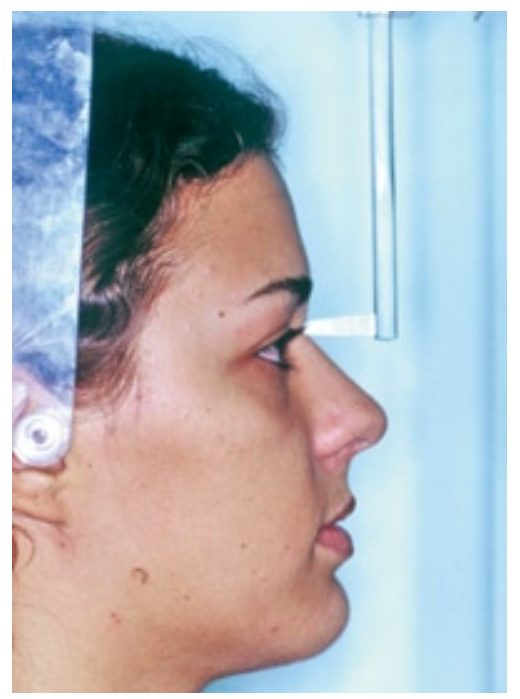

FIGURA 5 - Fotografia perfil de uma paciente Padrão I, Classe I.

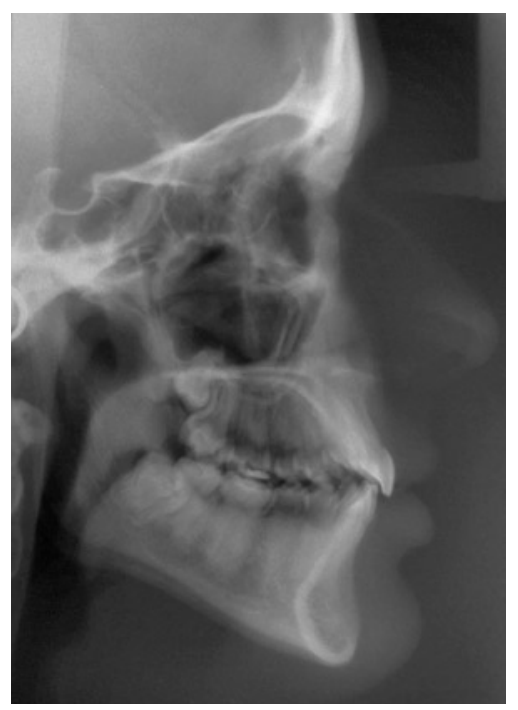

FIGURA 6 - Telerradiografia em norma lateral de uma paciente Padrão I, Classe I. 
levemente convexo; 2) terços faciais proporcionais; 3) linha queixo-pescoço paralela ao plano de Câmper; 4) sulco lábio-mentoniano normal, com igual participação do mento e do lábio (Fig. 4 a 6). Além disso, nenhum deles foi submetido ao tratamento ortodôntico prévio.

Após a seleção dos 39 indivíduos ${ }^{36}$, com base na avaliação da morfologia facial, suas respectivas radiografias cefalométricas foram utilizadas, tendo sido selecionadas com os mesmos requisitos técnicos adotados para o grupo composto por indivíduos Padrão Face Longa. Dos indivíduos selecionados para essa amostra, 26 eram do gênero feminino $(66,67 \%)$ e 13 do gênero masculino $(33,33 \%)$ (Tab. 1). Uma idade média de 22 anos e 10 meses ( $d p=2$ anos e 10 meses) foi observada para a amostra total, sendo 19 anos e 7 meses $(\mathrm{dp}=3$ anos e 1 mês) e 22 anos e 8 meses ( $d p=2$ anos e 5 meses) as médias e desvios-padrão, respectivamente, para os gêneros feminino e masculino (Tab. 2).

\section{Método}

As telerradiografias cefalométricas laterais foram digitalizadas por meio do scanner, sendo as imagens submetidas à análise do programa Radiocef 2.0, seguindo as normas especificadas pelo fabricante ${ }^{44}$. Os resultados foram armazenados e posteriormente submetidos à avaliação estatística.

Para a obtenção das medidas lineares, angulares e proporcionais, a demarcação dos pontos previamente estabelecidos foi realizada nas imagens escaneadas das telerradiografias cefalométricas laterais, por um único observador.

\section{Medidas lineares}

Para o estudo, as medidas lineares utilizadas ${ }^{37}$ estão ilustradas nas figuras 7 a 9. Vale destacar apenas algumas, por não serem medidas convencionais:

- DifMxMd - diferencial Maxilo-Mandibular, sendo a diferença entre as medidas do Co-Gn e Co-A;

- AFATperp (altura facial anterior total perpendicular) - altura facial anterior total, mensurada en- tre o ponto $\mathrm{N}$ e a projeção do ponto Me na linha $\mathrm{N}$ perpendicular, definida por Capelozza Filho et al. ${ }^{10}$;

- AFAIperp (altura facial anterior inferior perpendicular) - altura facial anterior inferior, mensurada entre a projeção dos pontos ENA e Me na linha $\mathrm{N}$ perpendicular ${ }^{10}$;

- 1-PP - distância ortogonal do ápice radicular do incisivo central superior ao plano palatino, for-

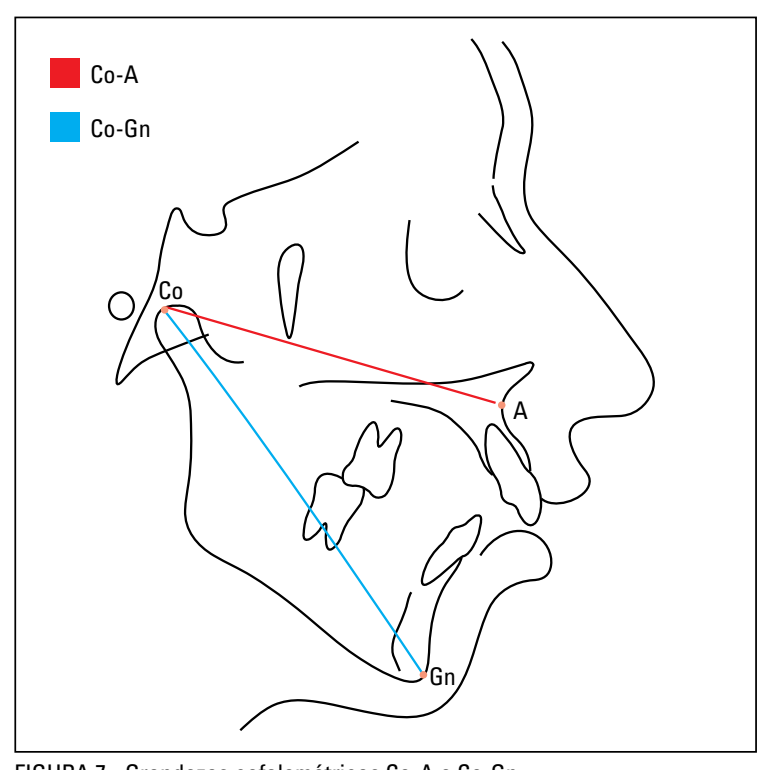

FIGURA 7 - Grandezas cefalométricas Co-A e Co-Gn.

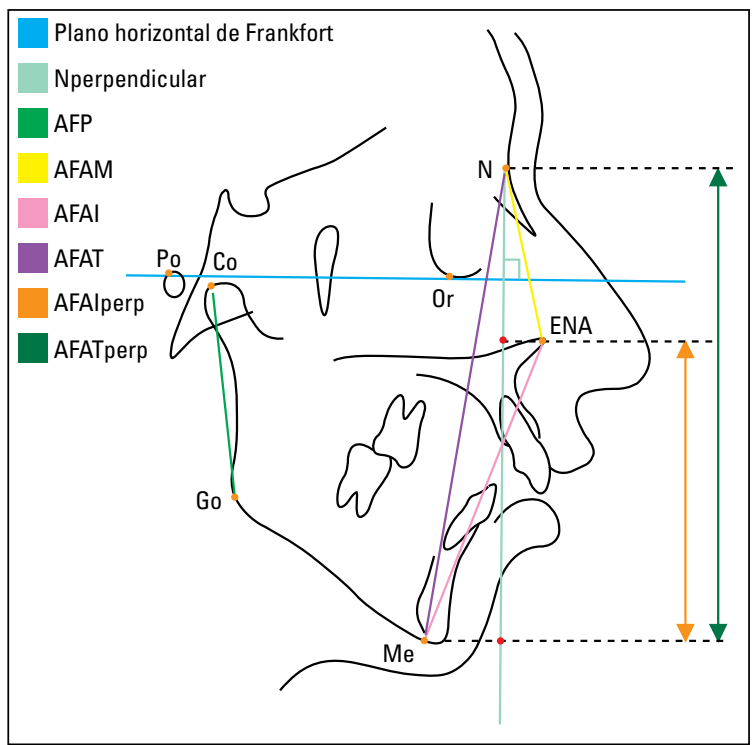

FIGURA 8 - Plano horizontal de Frankfort, Nperpendicular e grandezas cefalométricas AFP, AFAM, AFAI, AFAT, AFAlperp, AFATperp. 
mado pela união dos pontos ENA e ENP;

- 6-PP - distância ortogonal do ápice da raiz mesial do primeiro molar superior ao plano palatino, formado pela união dos pontos ENA e ENP;

- 1-PM - distância ortogonal do ápice radicular do incisivo central inferior ao plano mandibular, formado pela união dos pontos Go e Me;

- 6-PM - distância ortogonal do ápice da raiz

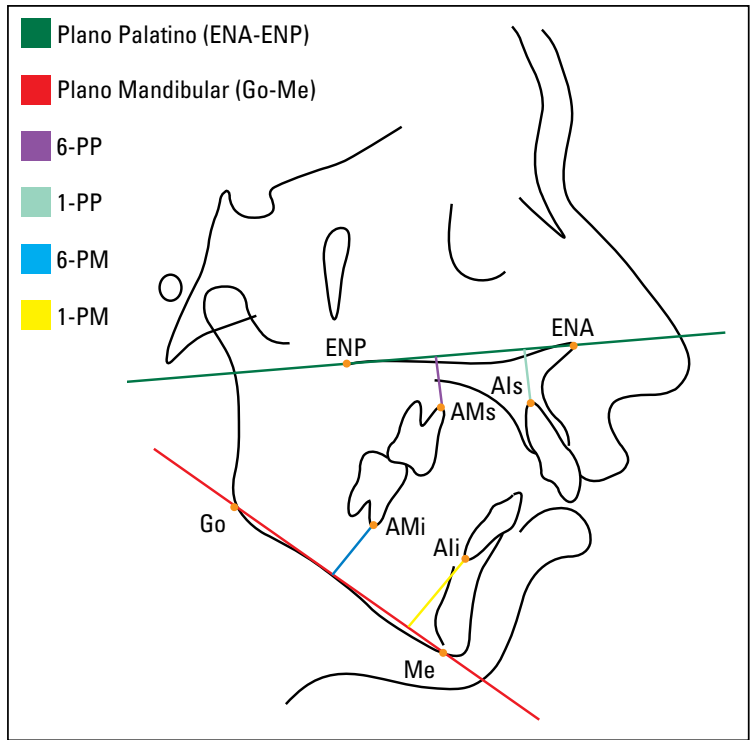

FIGURA 9 - Plano Palatino, Plano Mandibular e grandezas cefalométricas 6-PP, 1-PP, 6-PM e 1-PM.

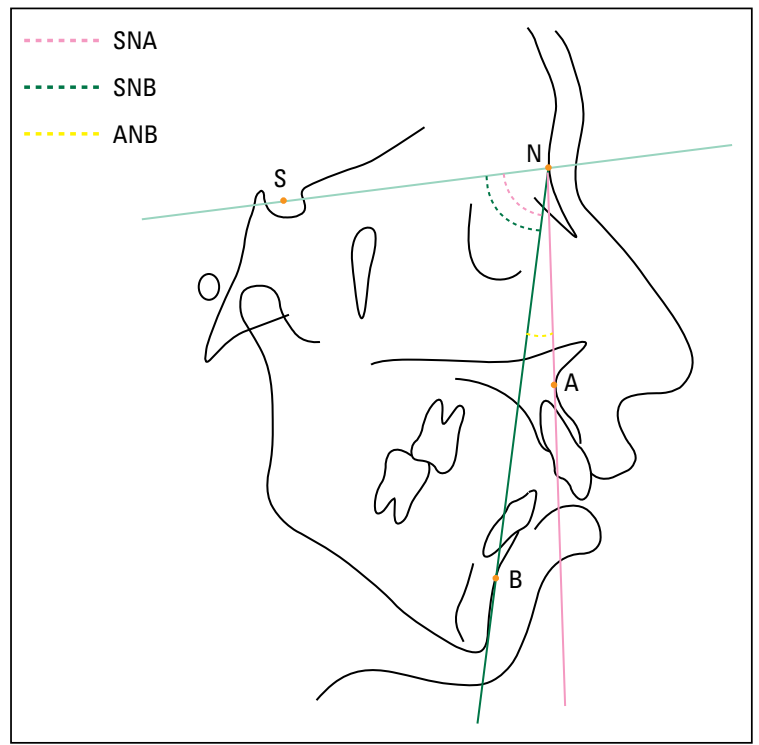

FIGURA 10 - Grandezas cefalométricas SNA, SNB e ANB. mesial do primeiro molar inferior ao plano mandibular, formado pela união dos pontos Go e Me.

\section{Medidas angulares}

Para o estudo, as medidas angulares utilizadas $^{37}$ estão ilustradas nas figuras 10 a 12. Vale destacar apenas algumas, por não serem medidas convencionais:

- AnGon (Ângulo Goníaco) - ângulo formado pela interseção das linhas C-Go e Go-Me;

- AnPP (Ângulo do Plano Palatino) - ângulo formado pela confluência das linhas S-N e ENA-ENP;

- Al/3IF (Ângulo do terço inferior da face) formado pelas linhas ENA-Me e Go-Me;

- AnPM (Ângulo do Plano Mandibular) - ângulo formado pela confluência das linhas S-N e Go-Gn;

\section{Medidas de proporção}

Para o estudo, as seguintes medidas proporcionais foram utilizadas, sendo definidas abaixo:

- AFAIperp/AFATperp - proporção existente entre a altura facial anterior inferior e a altura facial anterior total, projetadas na linha $\mathrm{N}$ perpendicular;

- AFAI/AFAT - proporção existente entre a altura facial anterior inferior e a altura facial anterior total;

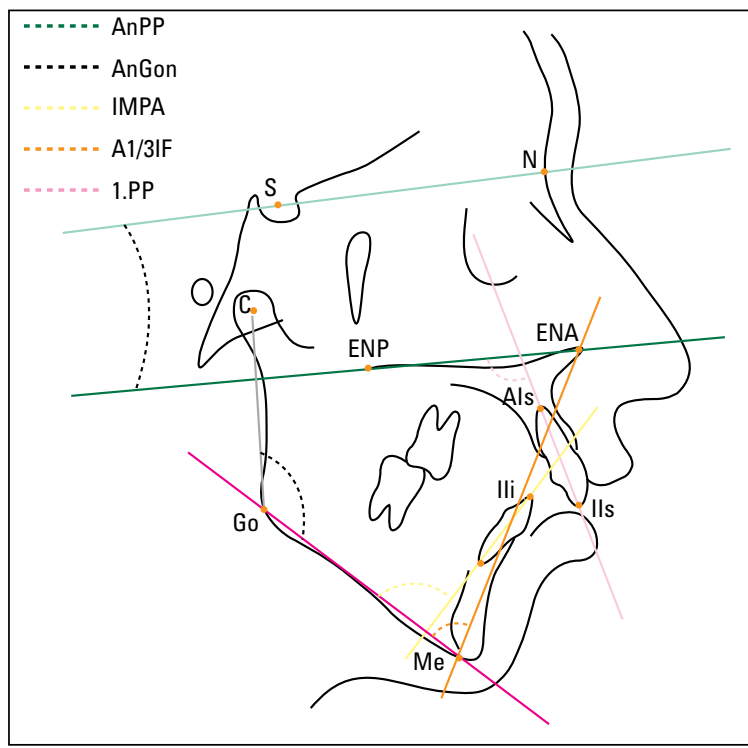

FIGURA 11 - Grandezas cefalométricas AnPP, AnGon, IMPA, A1/3IF e 1.PP. 


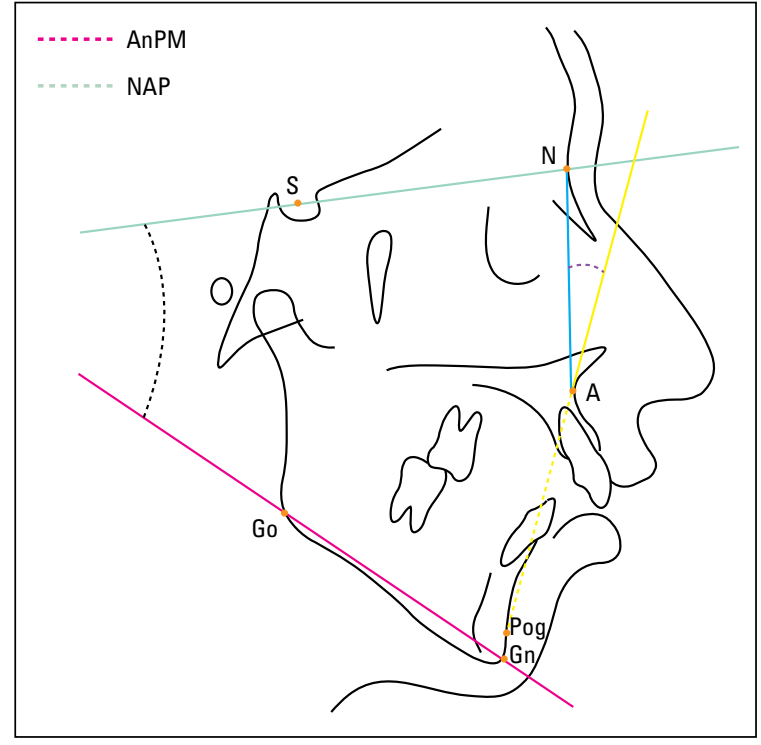

FIGURA 12 - Grandezas cefalométricas AnPM e NAP.

- AFAM/AFAI - proporção existente entre a altura facial anterior média e a altura facial anterior inferior;

- AFP/AFAT - proporção existente entre a altura facial posterior e a altura facial anterior total.

\section{Análise estatística}

Para todas as variáveis mensuradas, foram calculadas suas médias e desvios-padrão, bem como os seus valores máximos e mínimos. Com o objetivo de detectar as diferenças entre os grupos estudados, utilizou-se o teste " $t$ " para dados independentes. Foram comparados os grupos Padrão I e Padrão Face Longa, sem distinção de gêneros, estabelecendo-se $5 \%(\mathrm{p}<0,05)$ de nível de significância para as comparações realizadas.

Para a verificação do erro do método, 22 telerradiografias foram aleatoriamente escolhidas, cujos pontos foram novamente demarcados, e as mensurações refeitas pelo programa Radiocef $2.0^{44}$. Os valores obtidos na primeira e na segunda mensuração foram submetidos ao teste " $\mathrm{t}$ ", para o estudo do erro sistemático, e à fórmula de Dahlberg, para o estudo do erro casual.

Na tabela 3, estão demonstrados os resultados da estimativa do erro do método pelo teste " $t$ " e segundo Dahlberg (apud HOUSTON ${ }^{21}$, 1983), respectivamente, para o erro sistemático e o erro casual ou

\begin{tabular}{|c|c|c|c|c|c|c|c|}
\hline \multirow[b]{2}{*}{ Medida } & \multicolumn{2}{|c|}{$1^{\mathrm{a}}$ mensuração } & \multicolumn{2}{|c|}{$2^{\mathrm{a}}$ mensuração } & \multirow{2}{*}{$\mathbf{t}$} & \multirow{2}{*}{$\mathbf{p}$} & \multirow{2}{*}{ Dahlberg } \\
\hline & $\mathbf{x}$ & $d p$ & $\mathbf{x}$ & dp & & & \\
\hline Co-Gn & $125,23 \mathrm{~mm}$ & $8,78 \mathrm{~mm}$ & $124,99 \mathrm{~mm}$ & $8,69 \mathrm{~mm}$ & 1,065 & 0,299 & $0,747 \mathrm{~mm}$ \\
\hline Co-A & $94,96 \mathrm{~mm}$ & $6,78 \mathrm{~mm}$ & $94,9 \mathrm{~mm}$ & $7,15 \mathrm{~mm}$ & 0,207 & 0,838 & $1,008 \mathrm{~mm}$ \\
\hline AFAT & $130,91 \mathrm{~mm}$ & $10,1 \mathrm{~mm}$ & $130,87 \mathrm{~mm}$ & $10,1 \mathrm{~mm}$ & 0,149 & 0,883 & $0,808 \mathrm{~mm}$ \\
\hline AFAI & $76,78 \mathrm{~mm}$ & $8,01 \mathrm{~mm}$ & $76,62 \mathrm{~mm}$ & $8,23 \mathrm{~mm}$ & 0,758 & 0,457 & $0,714 \mathrm{~mm}$ \\
\hline AFAM & $56,96 \mathrm{~mm}$ & $4,08 \mathrm{~mm}$ & $56,95 \mathrm{~mm}$ & $3,8 \mathrm{~mm}$ & 0,052 & 0,959 & $0,666 \mathrm{~mm}$ \\
\hline AFP & $62,74 \mathrm{~mm}$ & $6,17 \mathrm{~mm}$ & $62,78 \mathrm{~mm}$ & $5,56 \mathrm{~mm}$ & 0,073 & 0,943 & $1,822 \mathrm{~mm}$ \\
\hline AFATperp & $130,18 \mathrm{~mm}$ & $9,7 \mathrm{~mm}$ & $130,08 \mathrm{~mm}$ & $9,68 \mathrm{~mm}$ & 0,4 & 0,693 & $0,833 \mathrm{~mm}$ \\
\hline AFAlperp & $73,92 \mathrm{~mm}$ & $6,77 \mathrm{~mm}$ & $73,71 \mathrm{~mm}$ & $6,91 \mathrm{~mm}$ & 0,906 & 0,375 & $0,797 \mathrm{~mm}$ \\
\hline 1-PP & $8,42 \mathrm{~mm}$ & $3,31 \mathrm{~mm}$ & $8,37 \mathrm{~mm}$ & $3,34 \mathrm{~mm}$ & 0,174 & 0,864 & $0,954 \mathrm{~mm}$ \\
\hline 6-PP & $7,68 \mathrm{~mm}$ & $2,96 \mathrm{~mm}$ & $7,71 \mathrm{~mm}$ & $2,8 \mathrm{~mm}$ & 0,161 & 0,874 & $0,684 \mathrm{~mm}$ \\
\hline 1-PM & $20,48 \mathrm{~mm}$ & $3,14 \mathrm{~mm}$ & $20,81 \mathrm{~mm}$ & $3,3 \mathrm{~mm}$ & 0,727 & 0,475 & $1,547 \mathrm{~mm}$ \\
\hline 6-PM & $12,52 \mathrm{~mm}$ & $4,03 \mathrm{~mm}$ & $12,73 \mathrm{~mm}$ & $3,59 \mathrm{~mm}$ & 0,575 & 0,571 & $1,224 \mathrm{~mm}$ \\
\hline SNA & $81,1^{\circ}$ & $3,7^{\circ}$ & $81,25^{\circ}$ & $3,47^{\circ}$ & 0,537 & 0,597 & $0,947^{\circ}$ \\
\hline SNB & $76,49^{\circ}$ & $4,93^{\circ}$ & $76,68^{\circ}$ & $4,94^{\circ}$ & 1,039 & 0,31 & $0,641^{\circ}$ \\
\hline AnGon & $125,59^{\circ}$ & $5,78^{\circ}$ & $125,75^{\circ}$ & $5,37^{\circ}$ & 0,461 & 0,649 & $1,114^{\circ}$ \\
\hline AnPM & $35,81^{\circ}$ & $8,69^{\circ}$ & $35,61^{\circ}$ & $8,69^{\circ}$ & 0,717 & 0,481 & $0,941^{\circ}$ \\
\hline AnPP & $9,11^{\circ}$ & $3,47^{\circ}$ & $9,09^{\circ}$ & $3,58^{\circ}$ & 0,081 & 0,936 & $0,879^{\circ}$ \\
\hline 1.PP & $112,74^{\circ}$ & $7,8^{\circ}$ & $112,43^{\circ}$ & $8,15^{\circ}$ & 0,575 & 0,572 & $1,819^{\circ}$ \\
\hline IMPA & $92,11^{\circ}$ & $7,1^{\circ}$ & $92,76^{\circ}$ & $7,02^{\circ}$ & 1,022 & 0,318 & $1,809^{\circ}$ \\
\hline $\mathrm{A} 1 / 3 \mathrm{IF}$ & $76,31^{\circ}$ & $5,47^{\circ}$ & $76,17^{\circ}$ & $5,25^{\circ}$ & 0,366 & 0,718 & $1,316^{\circ}$ \\
\hline NAP & $8,45^{\circ}$ & $6,84^{\circ}$ & $8,09^{\circ}$ & $6,8^{\circ}$ & 1,32 & 0,201 & $0,93^{\circ}$ \\
\hline
\end{tabular}


aleatório. De acordo com a estimativa do erro do método, não foram detectadas diferenças estatisticamente significantes quanto ao erro sistemático, enquanto que os valores do erro casual obtidos encontravam-se dentro de um limite tolerável ${ }^{46}$.

\section{RESULTADOS}

Os resultados obtidos neste estudo foram distribuídos em tabelas. Os valores médios, mínimos e máximos, além dos respectivos desvios-padrão das grandezas mensuradas a partir das duas amostras, Padrão I e Padrão Face Longa, foram descritos, respectivamente, nas tabelas 4 e 5 .

Os resultados das comparações entre a amostra Padrão I e Padrão Face Longa, estão descritos na tabela 6.

\section{DISCUSSÃO}

O Padrão Face Longa é uma deformidade vertical de prevalência relativamente pequena, acometendo aproximadamente $1,5 \%$ da população mundial ${ }^{17}$. Em vista disso, a amostra de 34 casos utilizada pelo presente estudo pode ser considerada aceitável e conclusões confiáveis podem ser extraídas dele, visto que amostras de tamanhos compativeis foram encontradas na literatura ${ }^{27}$ para 0 mesmo padrão de deformidade estudado.

De forma geral, os indivíduos Padrão Face Longa apresentaram grandes desvios em relação aos indivíduos Padrão I, demonstrando significativo impacto estético ocasionado pela displasia vertical. A existência de um protocolo ortodôntico-cirúr-

\begin{tabular}{|c|c|c|c|c|c|}
\hline Variáveis & Unidade & Médias(PI) & Mínimo & Máximo & dp \\
\hline Co-Gn & $\mathrm{mm}$ & 124,63 & 108,71 & 138,35 & 8,18 \\
\hline Co-A & $\mathrm{mm}$ & 95,24 & 84,56 & 105,46 & 5,55 \\
\hline DifMxMd & $\mathrm{mm}$ & 29,39 & 19,04 & 40,26 & 4,78 \\
\hline AFAT & $\mathrm{mm}$ & 124,43 & 107,39 & 146,34 & 8,82 \\
\hline AFAI & $\mathrm{mm}$ & 70,14 & 53,55 & 85,02 & 6,95 \\
\hline AFAM & $\mathrm{mm}$ & 56,18 & 47,71 & 64,14 & 3,51 \\
\hline AFP & $\mathrm{mm}$ & 63,12 & 52,75 & 76,56 & 5,27 \\
\hline AFATperp & $\mathrm{mm}$ & 124,23 & 107,38 & 145,2 & 8,78 \\
\hline AFAlperp & $\mathrm{mm}$ & 68,73 & 53,10 & 82,17 & 6,77 \\
\hline 1-PP & $\mathrm{mm}$ & 6,12 & 2,30 & 9,94 & 1,94 \\
\hline 6-PP & $\mathrm{mm}$ & 5,35 & 0,53 & 10,36 & 2,16 \\
\hline 1-PM & $\mathrm{mm}$ & 18,53 & 12,70 & 24,66 & 3,08 \\
\hline 6-PM & $\mathrm{mm}$ & 11,64 & 5,52 & 20,58 & 3,44 \\
\hline SNA & graus & 82,37 & 74,32 & 90,01 & 3,14 \\
\hline SNB & graus & 79,63 & 73,65 & 86,39 & 2,46 \\
\hline ANB & graus & 2,75 & $-0,73$ & 9,61 & 2,00 \\
\hline AnGon & graus & 121,13 & 109,08 & 133,04 & 5,27 \\
\hline AnPM & graus & 29,44 & 20,80 & 39,07 & 4,27 \\
\hline AnPP & graus & 9,23 & 2,87 & 15,87 & 3,02 \\
\hline 1.PP & graus & 114,34 & 98,44 & 129,96 & 6,81 \\
\hline IMPA & graus & 94,05 & 81,69 & 107,70 & 6,28 \\
\hline $\mathrm{A} 1 / 3 \mathrm{IF}$ & graus & 78,73 & 69,69 & 87,60 & 4,57 \\
\hline NAP & graus & 4,29 & 0,16 & 19,29 & 3,89 \\
\hline AFAlperp/AFATperp & - & 0,55 & 0,49 & 0,59 & 0,02 \\
\hline AFAI/AFAT & - & 0,56 & 0,50 & 0,60 & 0,03 \\
\hline AFAM/AFAI & - & 0,81 & 0,68 & 1,03 & 0,08 \\
\hline AFP/AFAT & - & 0,51 & 0,43 & 0,59 & 0,04 \\
\hline
\end{tabular}




\begin{tabular}{|c|c|c|c|c|c|}
\hline Variáveis & Unidade & Médias(PFL) & Mínimo & Máximo & $d p$ \\
\hline Co-Gn & $\mathrm{mm}$ & 123,15 & 107,24 & 146,33 & 10,68 \\
\hline Co-A & $\mathrm{mm}$ & 91,45 & 82,07 & 109,22 & 5,89 \\
\hline DifMxMd & $\mathrm{mm}$ & 31,70 & 20,32 & 55,15 & 8,64 \\
\hline AFAT & $\mathrm{mm}$ & 135,54 & 119,29 & 160,80 & 10,10 \\
\hline AFAI & $\mathrm{mm}$ & 82,41 & 69,57 & 101,92 & 7,12 \\
\hline AFAM & $\mathrm{mm}$ & 56,62 & 48,43 & 68,13 & 4,00 \\
\hline AFP & $\mathrm{mm}$ & 59,11 & 47,16 & 77,88 & 6,05 \\
\hline AFATperp & $\mathrm{mm}$ & 134,06 & 117,80 & 156,81 & 10,04 \\
\hline AFAlperp & $\mathrm{mm}$ & 78,07 & 66,84 & 100,68 & 7,50 \\
\hline 1-PP & $\mathrm{mm}$ & 9,98 & 4,29 & 16,55 & 3,18 \\
\hline 6-PP & $\mathrm{mm}$ & 7,94 & 0,83 & 15,99 & 3,43 \\
\hline 1-PM & $\mathrm{mm}$ & 21,53 & 16,41 & 26,59 & 2,75 \\
\hline 6-PM & $\mathrm{mm}$ & 12,35 & 5,58 & 21,07 & 3,61 \\
\hline SNA & graus & 79,92 & 72,06 & 88,03 & 3,56 \\
\hline SNB & graus & 74,08 & 64,83 & 84,52 & 4,94 \\
\hline ANB & graus & 5,84 & $-0,88$ & 13,59 & 3,79 \\
\hline AnGon & graus & 131,59 & 119,17 & 143,43 & 5,86 \\
\hline AnPM & graus & 43,99 & 31,78 & 55,57 & 6,82 \\
\hline AnPP & graus & 8,76 & 1,65 & 16,85 & 3,92 \\
\hline 1.PP & graus & 111,50 & 84,03 & 127,33 & 8,20 \\
\hline IMPA & graus & 88,39 & 71,38 & 102,80 & 7,44 \\
\hline $\mathrm{A} 1 / 3 \mathrm{IF}$ & graus & 71,77 & 56,33 & 84,25 & 7,21 \\
\hline NAP & graus & 10,60 & 0,77 & 28,37 & 7,31 \\
\hline AFAlperp/AFATperp & - & 0,58 & 0,54 & 0,64 & 0,02 \\
\hline AFAI/AFAT & - & 0,61 & 0,58 & 0,65 & 0,02 \\
\hline AFAM/AFAI & - & 0,69 & 0,57 & 0,78 & 0,04 \\
\hline AFP/AFAT & - & 0,44 & 0,37 & 0,53 & 0,04 \\
\hline
\end{tabular}

\begin{tabular}{|c|c|c|c|c|c|c|c|}
\hline \multicolumn{8}{|c|}{ Tabela 6 - Comparação entre os grupos Padrão I e Padrão Face Longa pelo teste "t" de Student. } \\
\hline Variáveis & Unid & Médias (PI) & dp & Médias (PFL) & $d p$ & $t$ & p \\
\hline Co-Gn & $\mathrm{mm}$ & 124,63 & 8,18 & 123,15 & 10,68 & 0,665 & $>0,05$ \\
\hline Co-A & $\mathrm{mm}$ & 95,24 & 5,55 & 91,45 & 5,89 & 2,829 & $<0,01^{*}$ \\
\hline DifMxMd & $\mathrm{mm}$ & 29,39 & 4,78 & 31,70 & 8,64 & 1,440 & $>0,05$ \\
\hline AFAT & $\mathrm{mm}$ & 124,43 & 8,82 & 135,54 & 10,10 & 5,017 & $0,001^{*}$ \\
\hline AFAl & $\mathrm{mm}$ & 70,14 & 6,95 & 82,41 & 7,12 & 7,437 & $0,001^{*}$ \\
\hline AFAM & $\mathrm{mm}$ & 56,18 & 3,51 & 56,62 & 4,00 & 0,505 & $>0,05$ \\
\hline AFP & $\mathrm{mm}$ & 63,12 & 5,27 & 59,11 & 6,05 & 3,029 & $<0,01^{*}$ \\
\hline AFATperp & $\mathrm{mm}$ & 124,23 & 8,78 & 134,06 & 10,04 & 4,465 & $<0,001^{*}$ \\
\hline AFAlperp & $\mathrm{mm}$ & 68,73 & 6,77 & 78,07 & 7,50 & 5,590 & $<0,001^{*}$ \\
\hline 1-PP & $\mathrm{mm}$ & 6,12 & 1,94 & 9,98 & 3,18 & 6,344 & $<0,001^{*}$ \\
\hline 6-PP & $\mathrm{mm}$ & 5,35 & 2,16 & 7,94 & 3,43 & 3,908 & $<0,001^{*}$ \\
\hline 1-PM & $\mathrm{mm}$ & 18,53 & 3,08 & 21,53 & 2,75 & 4,364 & $<0,001^{*}$ \\
\hline 6-PM & $\mathrm{mm}$ & 11,64 & 3,44 & 12,35 & 3,61 & 0,863 & $>0,05$ \\
\hline SNA & graus & 82,37 & 3,14 & 79,92 & 3,56 & 3,131 & $<0,01^{*}$ \\
\hline SNB & graus & 79,63 & 2,46 & 74,08 & 4,94 & 6,196 & $<0,001^{*}$ \\
\hline ANB & graus & 2,75 & 2,00 & 5,84 & 3,79 & 4,438 & $<0,001^{*}$ \\
\hline AnGon & graus & 121,13 & 5,27 & 131,59 & 5,86 & 8,027 & $<0,001^{*}$ \\
\hline AnPM & graus & 29,44 & 4,27 & 43,99 & 6,82 & 11,059 & $0,001^{*}$ \\
\hline AnPP & graus & 9,23 & 3,02 & 8,76 & 3,92 & 0,579 & $>0,05$ \\
\hline 1.PP & graus & 114,34 & 6,81 & 111,50 & 8,20 & 1,612 & $>0,05$ \\
\hline IMPA & graus & 94,05 & 6,28 & 88,39 & 7,44 & 3,520 & $<0,001^{*}$ \\
\hline $\mathrm{A} 1 / 3 \mathrm{IF}$ & graus & 78,73 & 4,57 & 71,77 & 7,21 & 4,986 & $<0,001^{*}$ \\
\hline \multirow{3}{*}{$\begin{array}{c}\text { NAP } \\
\text { AFAIperp/AFAT- } \\
\text { perp } \\
\text { AFAl/AFAT }\end{array}$} & graus & 4,29 & 3,89 & 10,60 & 7,31 & 4,687 & $<0,001^{*}$ \\
\hline & - & 0,55 & 0,02 & 0,58 & 0,02 & 5,640 & $<0,001^{*}$ \\
\hline & - & 0,56 & 0,03 & 0,61 & 0,02 & 8,756 & $<0,001^{*}$ \\
\hline AFAM/AFAI & - & 0,81 & 0,08 & 0,69 & 0,04 & 7,623 & $<0,001^{*}$ \\
\hline AFP/AFAT & - & 0,51 & 0,04 & 0,44 & 0,04 & 8,196 & $<0,001^{*}$ \\
\hline
\end{tabular}


gico padrão parece advir de um padrão de deformidade, incluindo impacção maxilar, osteotomia sagital bilateral mandibular e mentoplastia de reposição e/ou recolocação ${ }^{9,11}$.

Apesar da existência de algumas descrições cefalométricas sobre "face longa" na literatura, estas geralmente estavam vinculadas aos critérios oclusais ou cefalométricos adotados na seleção das amostras. Conseqüentemente, as conclusões estariam limitadas a apenas uma parte dos pacientes, uma vez que, por exemplo, nem todos os pacientes portadores do Padrão Face Longa apresentam mordida aberta anterior ${ }^{1,9,11,17,39}$. No presente estudo, o critério de seleção foi unicamente pelo aspecto facial, e como todos os indivíduos selecionados apresentavam para sua correção indicação ortodôntico-cirúrgica, dados mais reais e práticos para o diagnóstico puderam ser obtidos.

Em termos de prevalência do Padrão Face Longa (Tab. 1), parece que a deformidade é predominante para o gênero feminino, demonstrado também, coincidentemente, pela maior freqüência nas amostras utilizadas por Vig, Turvey ${ }^{45}$ e Haralabakis et al. ${ }^{20}$ Essa provável falsa impressão de que as mulheres compõem predominantemente a casuística de portadoras do Padrão Face Longa, deve ser atribuída a uma maior procura do tratamento, por representantes do gênero, em decorrência do prejuízo na estética facial.

Com o objetivo de facilitar a discussão dessas ocorrências, dividiu-se as várias características pesquisadas em tópicos, de acordo com as grandezas e as áreas craniofaciais.

\section{Padrão de crescimento facial}

Entre os três ângulos avaliados, isto é, ângulo do plano palatino, ângulo do plano mandibular e o ângulo goníaco, para determinar o padrão de crescimento facial, não foram observadas diferenças significantes para os valores do ângulo do plano palatino (Tab. 6). Esse e outros resultados encontrados no presente estudo confirmam que em indivíduos portadores de Padrão Face Longa, a deformidade reside predominantemente abaixo do plano palatino, conforme Frost et al. ${ }^{18}$, Cangialosi ${ }^{8}$ e Fields et al. ${ }^{15}$ afirmaram. Esse achado contrariou, entretanto, os resultados de Nahoum ${ }^{27}$ provavelmente devido a um menor valor da altura facial superior encontrado pelo autor.

Por outro lado, o ângulo do plano mandibular mostrou discrepâncias significativas quando os Grupos Padrão I e Padrão Face Longa foram comparados (Tab. 6), corroborando os resultados encontrados na literatura $2,4,5,8,15,16,17,18,20,22,27,28,32,33,47$. Os valores médios desse ângulo para os indivíduos Padrão Face Longa foram próximos aos valores máximos dos indivíduos Padrão I (Tab. 4 e 5). Isso implica na necessidade da associação de várias características cefalométricas para a definição de um Padrão Face Longa ${ }^{29}$. Em outras palavras, a utilização de valores numéricos de grandezas cefalométricas isoladas não é adequada para o diagnóstico.

Valores acima de $37^{\circ}$ para o ângulo do plano mandíbular foram relatados na literatura ${ }^{33}$ como parâmetro para definir indivíduos Padrão Face Longa. Embora os valores encontrados no presente estudo superem esse valor, os mesmos não podem ser utilizados isoladamente. Na verdade, a doença consiste em um desequilíbrio entre os componentes verticais e um parâmetro único não deveria ser adotado ${ }^{4,22,47}$. Ainda, segundo Van der Beek et al. ${ }^{42}$, esse ângulo apresentou maior correlação com a variação da altura facial anterior quando comparada à posterior, confirmando, novamente, a localização predominantemente ântero-inferior da discrepância nas displasias esqueléticas verticais.

Finalmente, os valores encontrados para o ângulo goníaco foram significantemente maiores (Tab. 6), corroborando os resultados relatados na literatu$\mathrm{ra}^{2,8,15,18,28,38,41}$, apesar de divergir com a ausência de significância estatística entre os Grupos Face Longa e Controle relatado por Nanda ${ }^{31}$. Sabe-se, clinicamente, que a morfologia mandibular encontra-se mais alterada do que o tamanho, propriamente dito, nos indivíduos Padrão Face Longa, nos quais o ângulo goníaco tende a ser obtuso devido ao crescimento horizontal do côndilo ${ }^{6}$. 
Alturas faciais anteriores e altura facial posterior Altura facial anterior total e altura facial anterior total perpendicular

$\mathrm{Na}$ mensuração da altura facial anterior total, duas grandezas cefalométricas foram utilizadas, a saber, altura facial anterior total (AFAT) e altura facial anterior total perpendicular (AFATperp), com o intuito de discriminar uma possivel falha na avaliação dessa dimensão apenas com a mensuração da distância linear existente entre os pontos $\mathrm{N}$ e Me. Partindo da premissa de que existe uma tendência de rotação no sentido póstero-inferior da mandíbula nos indivíduos Padrão Face Longa, essa rotação aumentaria o valor dessa distância, uma vez que o ponto Me apresentaria além de um deslocamento para baixo, um deslocamento para trás.

A hipótese aventada foi confirmada pelos resultados observados neste estudo. Nos indivíduos do grupo Padrão I, os valores das grandezas AFAT e AFATperp foram bem similares, enquanto que nos indivíduos $\mathrm{Pa}$ drão Face Longa foram diferentes, sendo maior para o valor da grandeza AFAT, expressando o efeito dessa rotação com a incorporação de pontos gerados pelo deslocamento para posterior (Tab. 5). Portanto, com finalidade de diagnóstico, é interessante considerar essa hipótese e utilizar apenas a avaliação perpendicular para definir a altura facial anterior total.

$\mathrm{Na}$ avaliação da diferença entre ambos os grupos estudados, quanto a essa característica, foi observada diferença significante entre os valores médios, tanto da AFAT como da AFATperp (Tab. 6). Esses resultados estavam de acordo com aqueles encontrados na literatura ${ }^{1,4,7,16,20,22,39,41}$.

Os valores médios de ambas as grandezas (AFAT e AFATperp) apresentados pelos indivíduos Padrão Face Longa foram significativamente maiores, porém, encontravam-se dentro dos limites de variação entre os valores mínimo e máximo das respectivas grandezas em indivíduos do grupo Padrão I. De posse desses resultados, o diagnóstico deve ser baseado na desproporção (desequilíbrio) dessas grandezas, não considerando valores lineares de forma isolada.

\section{Altura facial anterior média}

Não foi observada diferença estatisticamente significante para a altura da face média (AFAM) entre os indivíduos Padrão Face Longa e Padrão I (Tab. 6), corroborando os resultados encontrados na literatu$\mathrm{ra}^{1,5,18,30}$. Contrariamente, Nahoum ${ }^{27}$ encontrou valores menores para esta variável, quando avaliados indivíduos portadores da deformidade Face Longa. Admite-se, portanto, que a face média não é afetada de forma significativa pela deformidade estudada.

Altura facial anterior inferior e altura facial anterior inferior perpendicular

Assim como a altura facial anterior total, a altura facial anterior inferior foi também avaliada utilizandose duas grandezas cefalométricas, a saber, altura facial anterior inferior (AFAI) e altura facial anterior inferior perpendicular (AFAIperp), com a finalidade de superar o problema ocasionado pela rotação mandibular, que poderia influenciar sua avaliação. Os valores da AFAI, mensurados diretamente entre os pontos ENA e Me, perdem a representatividade quando ocorre alteração dimensional mandibular propriamente dita, como observado nos indivíduos Padrão II. Presumivelmente, a rotação distal da mandíbula incorpora pontos à distância, ou seja, ENA-Me (AFAI) dá a essa variável magnitude maior que a real ${ }^{10}$.

Similarmente aos resultados obtidos para a AFAT, os valores da AFAI também confirmaram essa hipótese. A AFAI sempre foi maior do que a AFAIperp, refletindo a somatória da quantidade de deslocamento distal do ponto Me à dimensão vertical, que era o objetivo dessa avaliação. Fica claro, portanto, que a avaliação das grandezas AFAI e AFAT, devem ser feitas sempre de maneira perpendicular.

De posse desse conceito e considerando seu uso rotineiro, os resultados encontrados neste trabalho para os valores da altura facial anterior inferior foram maiores para o grupo Padrão Face Longa (Tab. 6), com extrema significância estatística. Esse quadro era esperado, haja vista que o aumento da altura facial anterior inferior constitui a essência da doença estudada, sendo constatado freqüente- 
mente na literatura ${ }^{1,2,5,14,16,17,18,20,22,27,28,30,32,38,39,41,47}$.

De acordo com os resultados, os valores médios da AFAI e AFAIperp apresentados pelos indivíduos Padrão Face Longa estavam bem próximos, porém, inferiores aos valores máximos apresentados pelos indivíduos Padrão I (Tab. 4, 5). De forma similar ao discutido para as grandezas AFAT eAFATperp, mais do que um aumento nos valores da AFAI, é necessário que haja uma desproporção do incremento na altura facial anterior inferior, em relação às outras dimensões verticais, para determinar o Padrão Face Longa. Confirma-se, portanto, a contra-indicação na determinação e utilização de valores limítrofes para grandezas cefalométricas como indicativo no diagnóstico do Padrão Face Longa.

\section{Altura facial posterior}

A altura facial posterior apresentou um valor menor para o grupo Padrão Face Longa (Tab. 6). Essa diferença foi estatisticamente significante, corroborando os achados da literatura $4,8,18,20,22,28,33,38$. Esse dado, por sua vez, diferiu daquele relatado por Björk ${ }^{6}$, Fish et al. ${ }^{16}$ e Fitzpatrick ${ }^{17}$, que encontraram uma altura facial posterior aumentada para o grupo Padrão Face Longa. Ainda, outros autores $^{15,30,41}$ não observaram diferenças significantes quando os grupos estudados foram comparados.

Neste estudo, os valores da altura facial posterior dos indivíduos Padrão Face Longa foram inferiores aos dos indivíduos Padrão I (Tab. 4, 5), contribuindo, em associação com o incremento da AFAI, para gerar a característica do Padrão Face Longa.

Vale salientar que a controvérsia existente na literatura sobre a altura facial posterior implica que, no mínimo, esse é um fator menos significante, podendo ou não estar presente no Padrão Face Longa, ao contrário da altura facial anterior, que sempre está aumentada nesses pacientes. Esses resultados corroboram os de Van der Beek et al. ${ }^{42}$ que, em contraposição a uma menor influência da altura posterior da face, relataram uma maior influência da altura facial anterior na formação dos diferentes tipos faciais.

\section{Proporções entre as alturas faciais}

Para os indivíduos do grupo Padrão Face Longa, tão importante quanto observar as alterações ocorridas nas grandezas cefalométricas, foi considerar as proporções existentes entre as várias dimensões da face. A estética nesses indivíduos foi afetada, principalmente, devido a uma alteração desproporcional dessas dimensões.

Na realidade, como já havia sido discutido anteriormente, as alterações maiores ocorreram na altura facial anterior inferior. Isso acabou gerando alterações significativas em termos proporcionais quando essa variável esteve envolvida. Assim sendo, as proporções AFAI/AFAT e AFAIperp/AFATperp estavam aumentadas para os indivíduos Padrão Face Longa, devido aos valores maiores encontrados para a AFAI, enquanto que as proporções AFAM/AFAI e AFP/AFAT apresentavam valores menores em relação aos indivíduos Padrão I (Tab. 6), corroborando o estudo realizado por Bell ${ }^{4}$.

A proporção entre AFAI e AFAT observada neste estudo foi maior do que aquela encontrada por Isaacson et al. ${ }^{22}$ e semelhante aos achados de Schendel et al. ${ }^{39}$. O valor para a proporção entre AFAM e AFAI foi inferior ao observado por Nahoum et al. $^{28}$, Cangialosi ${ }^{8}$, Dung e Smith ${ }^{13}$, assim como a proporção existente entre AFP e AFAT em comparação com os achados da literatu$\mathrm{ra}^{8,13,33,39}$. Ainda com relação à proporção AFP/AFAT, os valores encontrados pelo presente estudo foram semelhantes aos de Isaacson et al. ${ }^{22}$

\section{Relação maxilo-mandibular e os comprimen- tos efetivos da maxila e da mandíbula}

A posição da maxila, avaliada pelo ângulo SNA, foi de retrusão em relação à base do crânio nos indivíduos Padrão Face Longa, apresentando diferença estatisticamente significante em relação aos indivíduos Padrão I (Tab. 6).

A retrusão maxilar provavelmente está associada a uma redução no comprimento efetivo da maxila, conforme foi verificado no presente estudo. Ao mesmo tempo, isso também pode ser resultado da 
redução do comprimento da maxila (ENA-ENP), observado por Haralabakis et al. ${ }^{20}$ Todavia, esse resultado diverge das observações da literatura ${ }^{1,16,17,39}$ onde não foram encontradas diferenças significantes quanto ao valor do ângulo SNA. Clinicamente, essa retrusão maxilar é freqüente e, muitas vezes, demanda um avanço maxilar como um dos procedimentos cirúrgicos no tratamento dos indivíduos portadores da deformidade face longa.

Com relação ao posicionamento mandibular, avaliado pelo ângulo SNB, esta estava acentuadamente retruída para os indivíduos Padrão Face Longa (Tab. 6), o que era esperado, já que a retrusão mandibular constitui uma das características do Padrão Face Longa 1,16,17,18,22,34,39,41,47. Por outro lado, essa retrusão não guardou correlação com o tamanho mandibular, uma vez que no comprimento efetivo da mandíbula, não foi observada diferença estatisticamente significante entre os grupos Padrão I e Padrão Face Longa, corroborando os achados de Sassouni e Nanda ${ }^{38}$ e contrariando os resultados obtidos por Subtelny e Sakuda ${ }^{41}$ (Tab. 6). Isso confirma a tendência de rotação mandibular, típica nesses indivíduos, podendo-se afirmar que a redução do ângulo SNB é conseqüência desse efeito rotacional.

A avaliação da relação maxilo-mandibular, baseada no valor do ângulo ANB, mostrou um degrau positivo mais acentuado nos indivíduos $\mathrm{Pa}$ drão Face Longa (Tab. 6). Isso reflete a tendência à relação molar Classe II que os portadores dessa deformidade apresentam ${ }^{1,9,11,16,17,22,39,47}$.

A retrusão mandibular foi enfatizada com a avaliação dos ângulos do terço inferior da face e NAP. Esses ângulos foram significativamente diferentes entre os grupos Padrão I e Padrão Face Longa, mostrando maior retrognatismo ou convexidade para esse último grupo (Tab. 6).

\section{Relações dentárias com as suas bases apicais}

As distâncias ortogonais verticais dos incisivos centrais superiores e inferiores em relação aos planos palatino e mandibular, respectivamente, mostraram diferenças significantes entre os indivíduos Padrão I e Padrão Face Longa (Tab. 6). Foi observado um aumento dessas distâncias, implicando a existência de uma compensação dentária a fim de camuflar a discrepância esquelética vertical. Essa característica parece ser unânime na literatura ${ }^{4,5,17,18,20,22,24,25,41,47}$. Por outro lado, Prittinem 33,34 afirmou que há mais extrusão dentária na região posterior, contrastando os resultados do presente estudo. Não obstante, Nahoum et al. ${ }^{28}$ afirmaram que as mesmas distâncias estavam diminuídas para o grupo Face Longa.

Apesar do afastamento vertical, os incisivos superiores estavam bem posicionados em relação às suas respectivas bases no sentido vestibulo-lingual (Tab. 6), corroborando os achados de Bell ${ }^{4}$ e discordando dos resultados encontrados por Gallangher et al. ${ }^{19}$. O mesmo não foi observado quando o posicionamento do incisivo inferior foi avaliado, encontrando-se inclinação lingual mais acentuada para o grupo Padrão Face Longa (Tab. 6), divergindo, nesse aspecto, dos resultados encontrados por Bell ${ }^{4}$. Do ponto de vista clínico é difícil questionar essa posição dos incisivos inferiores sendo resultado da compensação dentária no sentido vertical nesses indivíduos. Os incisivos, principalmente os inferiores, buscam manter relação de corte, extruindo e acabando por permanecer em um alvéolo restrito ao mínimo necessário para o seu suporte.

O aspecto da relação existente entre os molares superiores e as suas bases apicais foi similar àquele apresentado pelos incisivos, corroborando os achados de Wolford e Hilliard ${ }^{47}$ e, contrariamente, discordando dos achados de Nahoum et al. ${ }^{28}$ Não se observou o mesmo quadro de extrusão quando os primeiros molares inferiores foram avaliados, corroborando os achados de Nahoum et al. ${ }^{28}$ (Tab. 6).

A distância aumentada dos ápices dos primeiros molares superiores ao plano palatino representa um excesso posterior maxilar. Conseqüentemente, é razoável admitir que quando observado esse excesso vertical posterior na região maxilar, em indivíduos Padrão Face Longa, o agente etiológico primá- 
rio não seria o crescimento horizontal do côndilo, corroborando os achados na literatura ${ }^{17,18,20,26,31,39,40}$. Portanto, essa situação é diferente daquela descrita pelos trabalhos de Sassouni e Nanda ${ }^{38}$ e Björk ${ }^{6}$ em que o crescimento condilar é horizontal e a mandíbula sofre rotação no sentido horário. Nestes casos, como conseqüência, não é criado espaço vertical de crescimento posterior para a maxila ocupar e o excesso maxilar seria apenas anterior.

\section{CONCLUSÕES}

Considerando o método adotado e as suas limitações ${ }^{23}$, pôde-se concluir com o presente estudo que:

- o padrão de crescimento apresentado pelo grupo Face Longa foi vertical, sendo significativamente diferente daquele apresentado pelo grupo Padrão I. Além disso, a deformidade se localizou principalmente abaixo do plano palatino;

- quando comparado com o grupo Padrão I, a principal característica cefalométrica esquelética presente no grupo Padrão Face Longa foi o aumento da altura facial anterior inferior. Observouse, ainda, que essa alteração resulta no aumento da altura facial total, verificando-se uma proporção alterada na altura facial posterior;

- no Grupo Padrão Face Longa, observou-se presença de retrognatismo maxilar e mandibular.
A forma mandibular apresentou alteração significativa, com aumento do ângulo goníaco, sem contudo apresentar alteração no comprimento efetivo da mesma;

- as variáveis dentárias também se apresentaram alteradas, havendo uma excessiva extrusão dentária anterior (superior e inferior) e póstero-superior, não sendo o mesmo observado na região póstero-inferior. Os incisivos superiores estavam bem posicionados em sua base no grupo Padrão Face Longa, enquanto os incisivos inferiores encontravam-se lingualizados;

Os resultados permitiram concluir que alterações cefalométricas marcantes permeiam o esqueleto e a parte dentária dos indivíduos Padrão Face Longa. Seu diagnóstico radiográfico pode ser, portanto, facilmente determinado com base nas características cefalométricas determinadas neste trabalho.

\section{AGRADECIMENTO}

À empresa Radiomemory, a qual nos forneceu o software Radiocef 2.0, pelo constante suporte técnico fornecido durante a realização do estudo.

Enviado em: Janeiro de 2004

Revisado e aceito: Outubro de 2004

\section{Endereço para correspondência}

Mauricio de Almeida Cardoso

Disciplina de Ortodontia Preventiva - UNESP.

Rua José Bonifácio 1193 - Araçatuba/SP

CEP: 16015-050

E-mail: maucardoso@uol.com.br

\title{
Cephalometric characteristics assessment of long face pattern
}

\begin{abstract}
This study aimed to determine cephalometric characteristics of long face pattern patients in comparison to Class I pattern patients. A total of 73 lateral norm telerradiographs, 34 long face pattern and 39 Class I pattern individuals, were selected and compared with regards to facial morphology, not considering occlusal and sagital relationships. Additionally, evaluations were also made on facial growth pattern, anterior and posterior facial heights, maxillarymandibular relationship, as well as apical bases relationship and dental characteristics. In short, long face pattern individuals presented a large number of deviations compared to Class I pattern individuals, dysplasia being due to a disproportion among vertical components. It was observed that the values of variables TAFH, LAFH, TAFHperp, LAFHperp, 1-PP, 6-PP, 1-MP, SNB, ANB, goniac angle, mandibular plane angle, and the proportions among the facial heights were significantly altered in long face pattern individuals. Based on the results obtained from the present study, it has been verified that those individuals were characterized by the vertical growth pattern and by an increase of anterior and inferior facial height, the deformity being located below the palatal plane. It was also possible to verify a maxillary and mandibular retrognathism, as well as the presence of anterior (upper and lower) and posterosuperior dental extrusion, with apical incisors in apical base, and linguoclinated lower incisors.
\end{abstract}

Key words: Cephalometry. Corrective orthodontics. Deformities. Long Face Pattern. 


\section{REFERÊNCIAS}

1. ANGELILLO, J. C.; DOLAN, E. A. The surgical correction of vertical maxillary excess (long face syndrome). Ann Plast Surg, Boston, v. 8, p. 64-70, 1982.

2. ARVYSTAS, M. G. Treatment of anterior skeletal open-bite deformity. Am J Orthod, St. Louis, v. 72, p.147-164, 1977.

3. BEHRENTS, R. G. JCO intervews Dr. Rolf Behrents on adult craniofacial growth. J Clin Orthod, Hempstead, v. 20, p. 842-847, 1986.

4. BELL, W. H. Correction of skeletal type of anterior open bite. J Oral Surgery, Chicago, v. 29, p. 706-714, 1971.

5. BELL, W. H.; CREEKMORE, T. D.; ALEXANDER, R. G. Surgical correction of the long face syndrome. Am J Orthod, St. Louis, v. 71, p. 40-67, 1977.

6. BJÖRK, A. Prediction of mandibular growth rotation. Am J Orthod, St. Louis, v. 55, p. 585-599, 1969.

7. BLANCHETTE, M. E.; NANDA, R. S.; CURRIER, G. F.; GHOSH, J.; NANDA, S. K. A longitudinal cephalometric study of the soft tissue profile of short-and long-face syndromes from 7 to 17 years. Am J Orthod Dentofacial Orthop, St. Louis, v. 109, p.116-131, 1996.

8. CANGIALOSI, T. I. Skeletal morphologic features of anterior open bite. Am J Orthod Dentofacial Orthop, St. Louis, v. 85, p. 28-36, 1984.

9. CAPELOZZA FILHO, L. Diagnóstico em Ortodontia. 1. ed. Maringá: Dental Press Editora, 2004.

10. CAPELOZZA FILHO, L.; SOUZA, S. L. M. C.; CAVASSAN, A. O.; OZAWA, T. O. A altura facial anterior inferior nas más oclusões do Padrão II, deficiência mandibular. R Dental Press Ortodon Ortop Facial, Maringá, v. 9, n. 6, p. 39-47, nov./dez. 2004

11. CARDOSO, M. A.; BERTOZ, F. A.; REIS, S. A. B.; CAPELOZZA FILHO, L. Estudo das características oclusais em portadores de padrão face longa com indicação de tratamento ortodônticocirúrgico. R Dental Press Ortodon Ortop Facial, Maringá, v. 7 , p. 63-70, 2002.

12. CARDOSO, M. A. Estudo das características cefalométricas do padrão face longa. 2003. 163 f. Dissertação (Mestrado em Odontologia)-Faculdade de Odontologia, Universidade Estadual "Júlio de Mesquita Filho", 2003.

13. DUNG, D. J.; SMITH, R. J. Cephalometric and clinical diagnosis of open bite tendency. . Am J Orthod Dentofacial Orthop, St. Louis, v. 94, no. 6, p. 484-490, 1988.

14. EPKER, B. N. Superior surgical repositioning of the maxilla: long term results. J Maxillofac Surg, Stuttgart, v. 9, p. 237-246, 1981.

15. FIELDS, H. W.; RPOFFIT, W. R.; NIXON, W. L.; PHILLIPS, C.; STANEK, E. Facial pattern differences in long-faced children and adults. Am J Orthod, St. Louis, v. 85, p. 217-223, 1984

16. FISH, L. C.; WOLFORD, L. M.; EPKER, B. N. Surgical-orthodontic correction of vertical maxillary excess. Am J Orthod, St. Louis, v. 73, p. 241-257, 1978.

17. FITZPATRICK, B. N. The long face and V. M. E. Aust Orthod J, Brisbane, v. 8, p. 82-89, 1984.

18. FROST, D. E.; FONSECA, R. J.; TURVEY, T. A.; HALL, D. J. Cephalometric diagnosis and surgical-orthodontic correction of apertognathia. Am J Orthod, St. Louis, v. 78, p. 657-669, 1980.

19. GALLANGHER, D. M.; BELL, W. H.; STORUM, K. A. Soft tissue changes associated with advancement genioplasty performed concomitantly with superior repositioning of the maxilla. J Oral Maxillofac Surg, Philadelphia, v. 42, p. 238-242, 1984.

20. HARALABAKIS, S.; YAGTZIS, S. C.; TOUTOUNTZAKIS, N. M. Cephalometric characteristics of open bite in adults: a three dimensional cephalometric evaluation. Int J Adult Orthod Orthog Surg, Chicago, v. 9, p. 222-232, 1994.

21. HOUSTON, W. J. The analysis of errors in orthodontic measurements. Am J Orthod, St. Louis, v. 83, p. 382-390, 1983.

22. ISAACSON, J. R.; ISAACSON, R. J.; SPEIDEL, T. M.; WORMS, F. W. Extreme variations in vertical facial growth and associated variation in skeletal and dental relations. Angle Orthod, Appleton, v.1, p. 219-229, 1971.

23. JACOBSON, A. Planning for orthognathic surgery: art or science? Int J Adult Orthodon Orthognath Surg, Chicago, v. 5, p. 217-224, 1990.
24. JANSON, G. R.; METAXAS, A.; WOODSIDE, D. G. Variation in maxillary and mandibular molar and incisor vertical dimension in 12-year-old subjects with excess, normal and short lower anterior face height. Am J Orthod Dentofacial Orthop, St. Louis, v.106, p. 409-418, 1994.

25. MERVILLE, L. C.; DINER, P. A. Long face: new proposals for taxonomy, diagnosis treatment. J Craniomaxillofac Surg, Stuttgart, v. 15, p. 84-93, 1987.

26. MOLONEY, F.; WEST, R. A.; McNEILL, W. Surgical correction of vertical maxillary excess: a re-evaluation. J Craniomaxillofac Surg, Stuttgart, v.10, p.84-91, 1982.

27. NAHOUM, H. I. Vertical proportions and the palatal plane in anterior open-bite. Am J Orthod, St. Louis, v. 59, p. 273-282, 1971.

28. NAHOUM, H. I.; HOROWITZ, S. L.; BENEDICTO, E. A. Varieties of anterior open-bite. Am J Orthod, St. Louis, v. 61, p. 486-492, 1972.

29. NAHOUM, H. I. Anterior open-bite: A cephalometric analysis and suggested treatment procedures. Am J Orthod, St. Louis, v. 67, p. 513-521, 1975.

30. NANDA, S. K. Patterns of vertical growth in the face. Am J Orthod Dentofacial Orthop, St. Louis, v. 93, p.103-116, 1988.

31. NANDA, S. K. Growth patterns in subjects with long and short faces. Am J Orthod Dentofacial Orthop, St. Louis, v.98, p. 247-258, 1990.

32. OPDEBEECK, H.; BELL, W. H.; EISENFELD, J.; MISHELEVIC, D. Comparative study between the SFS ans LFS rotation as a possible morphogenic mechanism. Am J Orthod, St. Louis, v. 74, p. 509-521, 1978.

33. PRITTINEN, J. R. Orthodontic diagnosis of long face syndrome. Gen Dent, Chicago, v. 44, p. 348-351, 1996.

34. PRITTINEN, J. R. Orthodontic management of long face syndrome. Gen Dent, Chicago, v. 45, p. 568-572, 1997.

35. REIS, S. A. B. Análise facial numérica e subjetiva do perfil e análise da relação oclusal sagital em brasileiros, adultos, leucodermas, não tratados ortodonticamente. 2001. $271 \mathrm{f}$. Dissertação (Mestrado em Ortodontia) - Faculdade de Odontologia, Universidade Metodista de São Paulo, 2001.

36. CAPELOZZA FILHO, L.; REIS, S. A. B.; SCANAVINNI, M. A.; CARDOSO, M. A. Características cefalométricas dos indivíduos padrão I. R Dental Press Ortodon Ortop Facial, Maringá, v.10, n. 1, p. 67-78, jan./fev. 2005.

37. RIOLO, M. L.; MOYERS, R. E.; McNAMARA JR., J. A. et al. An atlas of craniofacial growth. Ann Arbor: University of Michigan; Center for Human Growth and Development, 1974. Monograph 2, Craniofacial Growth Series.

38. SASSOUNI, V.; NANDA, S. Analysis of dentofacial vertical proportions. Am J Orthod, St. Louis, v. 50, p. 801-323, 1964.

39. SCHENDEL, S. A.; EISENFELD, J.; BELL, W. H.; EPKER, B. N.; MISHELEVICH, D. J. The long face syndrome: vertical maxillary excess. Am J Orthod, St. Louis, v. 70, p. 398-408, 1976.

40. SCHENDEL, S. A.; CARLOTTI JR., A. E. Variations of total vertical maxillary excess. J Oral Maxillofac Surg, Philadelphia, v. 43, p. 590-596, 1985.

41. SUBTELNY, J. D.; SAKUDA, M. Open-bite: diagnosis and treatment. Am J Orthod, St. Louis, v. 50, p. 337-358, 1964.

42. VAN DER BEEK, M. C. J.; HOEKSMA, J. B.; ANDERSEN, B. P. Vertical facial growth: a longitudinal study from 7 to 14 year of age. Eur J Orthod, London, v.13, p. 202-208, 1991.

43. VAN DER LINDEN, P. G. M. O desenvolvimento das faces longas e curtas e as limitações do tratamento. R Dental Press Ortodon Ortop Facial, Maringá, v. 4, p. 6-11, 1999.

44. VASCONCELOS, M. H. F. Avaliação de um programa de traçado cefalométrico. 2000. 178 f. Tese (Doutorado em Ortodontia)-Faculdade de Odontologia de Bauru, Universidade de São Paulo, Bauru, 2000.

45. VIG, K. W.; TURVEY, T. A. Surgical correction of vertical maxillary excess during adolescence. Int J Adult Orthod Orthognath Surg, Chicago, v. 4, p.119-128, 1989.

46. WAH, P. L.Y.; COOKE, M. S. Comparative cephalometric errors for orthodontic and surgical patients. Int J Adult Orthod Orthognath Surg, Chicago, v. 10, p.119-226, 1995.

47. WOLFORD, L. M.; HILLIARD, F. W. The surgical-orthodontic correction of vertical dentofacial deformities. J Oral Surg, Chicago, v. 39 , p. 883-897, 1981. 